
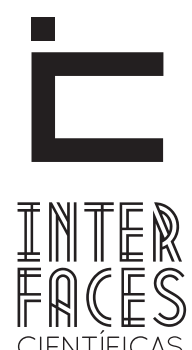

CIENTÍFICAS

HUMANASE SOCIAIS

ISSN IMPRESSO 2316-3348

E-ISSN 2316-3801

DOI - 10.17564/2316-3801.2019v7n3p115-130

\title{
PROESPORTE E A POLÍTICA DE INCENTIVO AO ESPORTE NA GESTÃO ESTADUAL DE GOIÁS: UM ESTUDO DESCRITIVO SOBRE OS LIMITES E AS POSSIBILIDADES EXISTENTES NAS POLÍTICAS PÚBLICAS PARA O ESPORTE GOIANO.
}

PROESPORTE AND THE POLICY OF ENCOURAGING SPORTS IN STATE MANAGEMENT OF GOIÁS: A DESCRIPTIVE STUDY ON THE LIMITS AND

POSSIBILITIES IN PUBLIC POLICIES FOR GOIÁS SPORT

PROESPORTE Y LA POLÍTICA DE INCENTIVO AL DEPORTE EN LA GESTIÓN ESTADUAL DE GOIÁS: UN ESTUDIO DESCRIPTIVO SOBRE LOS LÍMITES Y LAS POSIBILIDADES EXISTENTES EN LAS POLÍTICAS PÚBLICAS PARA EL DEPORTE DE GOIÁS

\section{RESUMO}

0 presente estudo enfoca as políticas públicas de esporte no contexto goiano, em especial sobre a política estadual de incentivo ao esporte instituída a partir da Lei $n^{0} 14.546 / 2003$ e tem por objetivo compreender o resultado das decisões engendradas ao longo do ciclo político no processo de construção de políticas públicas de esporte em Goiás. Pode-se constatar que como ocorre na esfera federal, no estado de Goiás a coalizão pró-EAR mantêm-se hegemônica e destaca-se enquanto esporte preponderante o futebol, uma vez que clubes esportivos de futebol têm recebido elevados valores de financiamento estadual por meio do Programa de Incentivo ao Esporte (PROESPORTE). Ou seja, por mais que as coalizões alternativas tendem a influenciar na nova conformação esportiva e na construção política, por meio da inclusão de novas dimensões esportivas vinculadas a concepção universalista, o mercado e os 
grandes "coronéis" do esporte ainda não "penduraram suas chuteiras”, mas pelo contrário têm mantido suas "chuteiras” fortemente ativas nesse jogo.

\section{ABSTRACT}

The present study focus on sports policies in the context of Goiás, in particular on sports policy instituted under Law 14.546/2003 and aims to understand the outcome of the decisions generated during the political cycle in the process. It is possible to observe that, as in the federal government, in the state of Goiás, the pro-EAR coalition remains hegemonic, and soccer is a prominent sport, since football sports clubs received high amounts of state funding through PROESPORTE. The alternative coalitions tend to influence the

\section{RESUMEN}

El presente estudio se centra en las políticas deportivas en el contexto de Goiás, en particular en la política deportiva instituida por la Ley 14.546 / 2003 y tiene como objetivo comprender el resultado de las decisiones generadas durante el ciclo político en el proceso. Es posible observar que, como en el gobierno federal, en el estado de Goiás, la coalición pro-EAR sigue siendo hegemónica, y el fútbol es un deporte destacado, ya que los clubes deportivos de fútbol recibieron grandes cantidades de fondos estatales a través de PROESPORTE. Tienden a influir en la nueva conformación deportiva y

\section{PALAVRAS-CHAVE}

Esporte. Política Pública. Administração Pública.

new sports conformation and political construction, through the inclusion of new sports dimensions linked to the universalist conception, the sports policies focus is the market and the great "colonels" of the sport have not yet "hung their boots" ,on the contrary have maintained their "boots" strongly active in that game.

\section{KEYWORDS}

Sport. Public Policy. Government. construcción política, a través de la inclusión de nuevas dimensiones deportivas vinculadas a la concepción universalista, las políticas deportivas se centran en el mercado y los grandes "coroneles" del deporte no han "colgado sus botas" Contrario han mantenido sus "botas" fuertemente activas en ese juego.

\section{PALABRAS CLAVE}

Desporte. Política Pública, Gobierno. 


\section{INTRODUÇ̃̃O}

Existem setores reconhecidos pelo Estado como áreas de domínio público, que tendem a ser considerados como elementos de pouca importância ou relevância perante aqueles setores essenciais à sobrevivência humana e da vida em sociedade. Essa conduta omissiva ocorre, geralmente, em relação aos campos de esporte, lazer e cultura. Mesmo que sejam legalmente considerados como direitos sociais e fundamentais ao exercício da cidadania, ao serem comparados às áreas de saúde, educação e segurança pública, por exemplo, são pouco debatidos pelo governo e, consequentemente, pela sociedade.

O esporte é considerado direito de todos e uma prática de exercício da cidadania desde a promulgação da Constituição Federal de 1988. 0 Estado, que antes vislumbrava o esporte apenas por seu caráter de rendimento, com o aparato constitucional de 1988, o legitima e o reconhece sob duas novas concepções para além do esporte de rendimento, o esporte educacional e o esporte social.

Art. $3^{\circ} \mathrm{O}$ desporto pode ser reconhecido em qualquer das seguintes manifestações:

I - desporto educacional, praticado nos sistemas de ensino e em formas assistemáticas de educação, evitando-se a seletividade, a hipercompetitividade de seus praticantes, com a finalidade de alcançar o desenvolvimento integral do indivíduo e a sua formação para o exercício da cidadania e a prática do lazer; II - desporto de participação, de modo voluntário, compreendendo as modalidades desportivas praticadas com a finalidade de contribuir para a integração dos praticantes na plenitude da vida social, na promoção da saúde e na educação e na preservação do meio ambiente;

III - desporto de rendimento, praticado segundo normas gerais desta Lei e regras de prática desportiva, nacionais e internacionais, com a finalidade de obter resultados e integrar pessoas e comunidades do País e estas com as de outras nações. (BRASIL, 1998, grifo nosso).

Não obstante, observa-se que, após mais de duas décadas sob esse arcabouço legal, as políticas desenvolvidas para o campo esportivo tornaram o esporte de alto rendimento, também intitulado esporte de es- petáculo, um campo hegemônico, que propicia a mercantilização da área e, logo, desprivilegia as políticas de esporte vinculadas à inclusão social. Ou seja, por meio de políticas de incentivos fiscais e transferência de fundos públicos para entidades não governamentais, o Estado deixa de promover iniciativas de elaboração de políticas públicas e sociais para o campo de esporte e lazer, transferindo essa responsabilidade para uma esfera não estatal.

Diversos fatores contribuem para essa ação estatal, inclusive para o baixo grau de importância destinado à área, já mencionado anteriormente. Outro ponto remete à articulação entre o Estado e o campo (neo)liberal que

\section{[...] constrói-se no imaginário coletivo uma perspecti- va de "ausência de perspectivas", segundo a qual não apenas Estado é ineficiente por natureza, como, na relação Estado-sociedade no Brasil, tudo tem perma- necido igual e nada jamais mudará, uma vez que os vícios desta relação são inerentes ao próprio Estado. Nesta perspectiva, o Estado não é passível de reforma, a não ser através de sua redução ao Estado mínimo. (FARAH, 2001 p. 120).}

O Estado, até o início da década de 1980, engendrava políticas públicas que incorporavam interesses da sociedade civil e do mercado de forma excludente e seletiva, beneficiando segmentos específicos (FARAH, 2001). Para Farah (2001) as políticas públicas desenvolvidas naquela ocasião eram fruto daqueles que detinham mais poder de barganha.

Após o processo de redemocratização, diversos movimentos societais e sociais exigiam uma reforma das políticas sociais e uma redefinição da agenda política. Contudo, a perspectiva neoliberal, que exigia a redução de ações e do papel estatal, logo se opõe à agenda formulada anteriormente pela sociedade civil e pelos movimentos sociais (FARAH, 2001).

No contexto esportivo, nota-se que, ao se tornar tema-pauta da agenda governamental, um tipo de esporte se destaca desde o processo de redemocratização brasileira - o esporte de alto rendimento, também denominado esporte-espetáculo -, sendo a dimensão esportiva fortemente engendrada pelo paradigma 
neoliberal. Ressalta-se a ocorrência de megaeventos esportivos financiados e desenvolvidos pela esfera federal, como a Copa Mundial de Futebol, em 2014, e as Competições Olímpicas de Verão, em 2016.

Ou seja, nesse contexto mercadológico e neoliberal "o esporte é atualmente um produto cultural altamente valorizado em todo o mundo, pelo menos no sentido econômico" (KUNZ, 2000, p. 23).

Parreira (2014) relata que a hegemonia do esporte-espetáculo advém da inserção do tema esporte na agenda governamental, ainda no Estado Novo, e questiona esse tipo de modelo esportivo que contraria os ditames constitucionais atuais, uma vez que impossibilita o acesso e a inclusão de todos. Ademais, o esporte deixa de ser tratado como direito social e adentra a dinâmica mercadológica, pois converte-se em bem de consumo.

O processo de mercantilização do esporte advém do alto volume de capital financeiro propiciado por patrocínios de eventos, equipes e atletas. Sigoli e Rose Júnior (2004, p. 118) destacam que:

\begin{abstract}
Este alinhamento do esporte aos entraves econômicos seguiu a ótica das políticas neoliberais consolidadas na década de 80. Os Estados nacionais passaram a ter menos influência política e as corporações transnacionais mais influência econômica. A desestatização do esporte e a inclusão do mesmo no mercado mundial caracterizaram as mudanças impostas pela globalização.
\end{abstract}

Assim, analisar e refletir sobre o produto advindo desse processo de decisão, de escolhas e de interações entre atores envolvidos nesse contexto de políticas de incentivo ao esporte possibilita uma discussão acerca dessas relações mercadológicas e de "privatização" de direitos sociais.

Observado o esporte enquanto um direito social, conforme estabelece a Constituição Federal de 1988, após a criação de lei específica que objetiva incentivar a prática esportiva e o seu desenvolvimento no estado de Goiás, a presente pesquisa visa responder as seguintes questões: que modelo esportivo tem sido fomentado e quais grupos são privilegiados pela política de incentivo de esporte na gestão estadual no estado de Goiás? Ou seja, quais são os limites e as possibilidades engendrados na construção da referida política pública?

Para isso, torna-se elucidativo a pesquisa acerca do campo de estudo de Política Pública, que se constituiu ao final do século XX, logo após a crise do Estado de Bem-Estar social. Embora formalmente seja um ramo da Ciência Política, a área de política pública pode ser objeto de análise de outras áreas de conhecimento, pois se integra a um campo multidisciplinar

De acordo com Trevisan e Bellen (2008), foram as convulsões econômicas, sociais e políticas que colocaram em xeque o papel do Estado, questionando tanto suas funções quanto a eficácia de suas ações interventoras na realidade social. Logo, coube ao campo de estudo de Política Pública investigar não apenas essas ações, mas todo o processo político que envolve a construção de políticas públicas.

Acerca das relações de poder e interações dos atores envolvidos no processo de consolidação de uma política pública, muitos autores tratam do tema sob essa perspectiva relacional. No entanto, neste estudo privilegiam-se os estudos de Sabatier e Jerkins-Smith (2007), em específico a teoria de coalizão de defesa (Advocacy Coalition Framework), no intento de compreender e refletir sobre a construção de políticas públicas de esporte e os resultados advindos dessas relações políticas nessa construção.

No que toca a formulação de políticas públicas, as diversas interpretações sobre o esporte e atores envolvidos, engendradas por crenças e valores diversificados, levam a tipos distintos de formulação e implementação de políticas para esse setor.

0 modelo de Sabatier e Jerkins-Smith (2007) preconiza que crenças, valores e ideias são importantes dimensões do processo de formulação de políticas públicas e influenciam nas demais etapas de constituição da política pública. A inclusão de valores societais é o fator distintivo desse modelo para com outros modelos que o antecederam.

Sabatier (1995) disserta que, para entender o processo de políticas públicas, é necessário analisar as divergências entre as abordagens de escolha racional e a $A C F$ : 
[] a abordagem de escolha racional diz que ao analista (1) focalizar os líderes institucionais como autoridade formal para a tomada de decisão; (2) assumir que estes estão buscando seu auto-interesse material (por exemplo, renda, poder, segurança) e (3) e a formulação são para grupos de atores inseridos em categorias institucionais, por exemplo, legisladores, agências administrativas e grupos de interesse (Shepsle 1989; Scharf 1997). Em contraste, a coalizão de defesa diz que o analista presume (1) que o sistema de crenças é mais importante que a afiliação institucional, (2) estes atores estão buscando uma ampla variedade de objetivos, que devem ser medidos empiricamente, e (3) deve-se adicionar pesquisadores, jornalistas como atores políticos potencialmente importantes. (SABATIER; JERKINS-SMITH, 2007, p. 4, tradução nossa).

Essas coalizões, compostas por grupos de interesse, atuam de forma a controlar o processo decisório de políticas públicas, seja a inclusão de um tema ou problema, ou, ao contrário, para que ele seja negligenciado. Tais ações, sejam de priorizar ou ocultar determinado tema, deixam explicitado a natureza e o escopo dos interesses envolvidos no "jogo" político entre os diversos atores; o processo de barganha e cooperação entre eles e os limites e as possibilidades advindas dessa interação e relação social e política (SABATIER; JERKINS-SMITH, 2007).

Percebe-se, discorrendo ainda sobre o campo de políticas públicas de esporte, que no século XXI existe uma defasagem, quantitativa e qualitativa, de programas e projetos para o campo, que decorre não só da fragilidade teórica, mas também de um campo empírico da área. Menicucci (2008, p. 187) afirma que

[...] a ausência de modelos analíticos mais robustos nos estudos em causa está relacionada com a própria fragilidade ainda do campo de conhecimento teórico relativo à análise de políticas públicas voltadas para o esporte e lazer em função mesmo da juventude dessa área de intervenção governamental [...].

Pode-se depreender, partindo da concepção teórica construída por Sabatier (1995), que atores e grupos que influenciam no processo decisório de uma política pública, em especial no tocante ao campo esportivo, têm corroborado à legitimação de um mo- delo esportivo que se vincula aos ideais mercadológicos e liberais e que se afasta do modelo compatível com os ditames constitucionais.

No tocante à inserção do tema esportivo na agenda governamental, é fundamental examinar a natureza e os interesses envolvidos na construção de políticas públicas para a área. A incorporação de pressupostos do modelo de coalizão de defesa no presente estudo propicia desenvolver reflexões sobre as políticas públicas de esporte, em especial no contexto local, e vislumbrar em que perspectiva se apoia essas políticas, se na perspectiva sociocultural ou na mercadológica-neoliberal.

\section{MATERIAL E MÉTODOS}

Acerca dos métodos e das técnicas utilizadas no decorrer da pesquisa, foram usados métodos mistos, uma vez que eles nos permitem evidenciar a importância teórica e prática do tema, bem como refletir e explorar o objeto e os problemas desta investigação. Reporta-se que presente trabalho tem por objetivo central compreender o resultado das decisões engendradas para o campo de políticas públicas de esporte, no contexto goiano, relacionado ao processo de escotha do modelo esportivo e beneficiários do Programa de Incentivo ao Esporte (PROESPORTE).

Destarte, a pesquisa toma a abordagem qualitativa como referência. Denzin (2006, p. 17) relata que "[...] a pesquisa qualitativa é atividade situada que localiza o observador no mundo. Consiste em um conjunto de práticas materiais e interpretativas que dão viabilidade ao mundo". Ademais, a abordagem qualitativa visa retratar os significados cotidianos e problemáticos existentes na vida dos indivíduos, propondo-se a captar sentidos implícitos existentes junto aos fenômenos investigados.

Ainda, utilizou-se a análise documental, técnica que busca, pela coleta de dados restrita aos documentos, escritos ou não, constituir o que se denomina de fontes primárias (LAKATOS; MARCONI, 2008). Dentre os documentos analisados aponta-se a Lei Estadual de Incentivo ao Esporte e demais docu- 
mentos acerca de programas e projetos que estejam vinculados à referida legislação.

Os dados sobre valores monetários, beneficiários e tipos de projetos foram coletados junto ao site institucional do governo de Goiás, na página exclusiva para o PROESPORTE. Os dados analisados foram apresentados por meio de fluxograma, quadros demonstrativos e representações gráficas (gráficos informativos do tipo circular).

Todo o processo de construção deste trabalho visa contribuir para uma reflexão direta sobre a relação entre o produto da decisão política e seu impacto na sociedade.

\section{RESULTADOS E DISCUSSÕES}

\subsection{CAMPO ESPORTIVO APÓS CONSTITUIÇÃO FEDERAL 1988}

Após o processo de redemocratização brasileira e a promulgação da Constituição Federal de 1988, coalizões alternativas fortaleceram a defesa de um modelo oposto ao difundido pelos "coronéis" do esporte brasileiro e inseriram na agenda político-institucional a concepção do esporte enquanto direito social. Ações políticas e governamentais começam a ser engendradas, visando garantir esse direito constitucional.

Esse movimento contra hegemônico, formando uma coalizão Pró-Esporte de Participação e Esporte Educacional (Pró-EPE), representa, para Bueno (2008), um processo de democratização esportiva, destacando dois fatores que foram cruciais para essa mudança paradigmática. Primeiramente, a mídia, pela imprensa, ao questionar o caráter unilateral do esporte, no caso o esporte de alto rendimento. Por conseguinte, a manifestação acadêmica e científica propiciou o aumento de estudos e trabalhos de cunho sociopolítico:
A democratização do esporte passou a ser debatida como questão de política pública pelo meio acadêmico, no qual o Colégio Brasileiro de Ciências do Esporte, CBCE, mostrou como agente crítico ao status quo e como espaço de reflexão e produção coletiva de conhecimento e respeito. (BUENO, 2008 p. 163).

Desse modo, o Estado e os políticos evidenciaram a necessidade, pressionados por atores sociais - como a mídia e os estudiosos da área -, de construir aportes legais que exteriorizassem uma perspectiva ampla do campo esportivo e que se remete ao fomento de categorias esportivas alternativas e diferentes daquela que se colocava hegemônica no país (BUENO, 2008).

Durante a década de 1990, o esporte experimentou várias configurações institucionais no bojo da administração pública federal. Hoje [pós-governo de Luiz Inácio ‘Lula' da Silva] o esporte no Brasil tem como entidade máxima de administração pública o Ministério do Esporte. (STAREPRAVO, 2011, p. 21).

O Estatuto do Desporto, pautado na Constituição Federal de 1988, revela, em seu artigo primeiro, que "É dever do Estado fomentar as práticas desportivas, como direito de cada um [...]" (BRASIL, 2001, p. 1). Assim, o esporte se torna um direito social, e mais, a partir de leis infraconstitucionais passa a ser um elemento a ser fomentado pelo Estado, garantindo a toda sociedade brasileira o direito às diversas manifestações desportivas.

A concepção tridimensional do esporte é recente no contexto brasileiro, marcada a partir da Constituição Federal de 1988. Antes do texto constitucional de 1988, no Brasil, o esporte de rendimento era reproduzido e disseminado tanto no ambiente escolar quanto fora do âmbito institucionalizado. Conforme quadro a seguir, é possível identificar as diferentes formas de exercício do direito ao esporte (TUBINO, 2010). 
Quadro 2 - Manifestações esportivas - formas, divisões e princípios

\begin{tabular}{|c|c|c|c|c|c|}
\hline \multicolumn{6}{|c|}{ ESPORTE } \\
\hline $\begin{array}{l}\text { Formas de } \\
\text { exercício do } \\
\text { direito ao }\end{array}$ & \multicolumn{2}{|c|}{ Esporte-Educação } & $\begin{array}{l}\text { Esporte de } \\
\text { Participação }\end{array}$ & \multicolumn{2}{|c|}{ Esporte de Desempenho } \\
\hline $\begin{array}{l}\text { Divisões das } \\
\text { formas de } \\
\text { exercício }\end{array}$ & Esporte Educacional & Esporte Escolar & Esporte-Lazer & $\begin{array}{l}\text { Esporte de } \\
\text { Rendimento }\end{array}$ & $\begin{array}{l}\text { Esporte de } \\
\text { Alto } \\
\text { Rendimento }\end{array}$ \\
\hline Princípios & $\begin{array}{c}\text { Participação } \\
\text { Coeducação } \\
\text { Cooperação } \\
\text { Corresponsa-bilidade } \\
\text { Inclusão }\end{array}$ & $\begin{array}{l}\text { Desenvolvimento } \\
\text { esportivo } \\
\text { Desenvolvimento do } \\
\text { espírito esportivo }\end{array}$ & $\begin{array}{l}\text { Participação } \\
\text { Prazer } \\
\text { Desenvolvimen- } \\
\text { to esportivo }\end{array}$ & \multicolumn{2}{|c|}{$\begin{array}{c}\text { Desenvolvimento esportivo } \\
\text { Superação }\end{array}$} \\
\hline
\end{tabular}

Fonte: Adaptado de Tubino (2010 p. 44).

A Constituição Federal de 1988 transformou a noção acerca do esporte "da água para o vinho", uma vez que trata o esporte sob um viés sociocultural, reconhecendo que o Estado necessitava aproximar o campo esportivo de uma concepção social e reduzir a intervenção do mercado nessa área.

\begin{abstract}
A mudança foi tão radical que não havia como considerar a Lei $n^{\circ} 6.251 / 75$, que passou a configurar autêntico entulho autoritário, tendo em vista as mudanças substantivas advindas do novo arcabouço legal constituído em 1988, no que concerne a área esportiva. Mesmo assim, levou quase cinco anos até que o país tivesse uma nova lei do desporto [...]. (BOUDIENS, 2002, p. 4).
\end{abstract}

O Estado e, em específico, os agentes eleitos e escolhidos pela sociedade de forma democrática são os responsáveis pela definição da agenda e pela elaboração/formulação de políticas pública. Organizados em arranjos políticos e coalizões políticas, determinam o tema da agenda e interferem na seleção das prioridades para alocação dos recursos públicos, logo na con- formação de uma política, um programa e/ou serviço (STAREPRAVO, 2011).

A demanda de novas concepções para o esporte e o lazer no Brasil, após o processo de redemocratização, exigia dos agentes recém-eleitos uma atitude política que corroborasse essa nova realidade para o esporte. Assim, a Lei no 8.672/1993, comumente conhecida como Lei Zico, surge como aparato legal capaz de representar essa nova concepção do campo esportivo, pautada na Constituição Federal de 1988:

Art. 217. É dever do Estado fomentar práticas desportivas formais e não-formais, como direito de cada um, observados:

I - a autonomia das entidades desportivas dirigentes e associações, quanto a sua organização e funcionamento; II - a destinação de recursos públicos para a promoção prioritária do desporto educacional e, em casos específicos, para a do desporto de alto rendimento;

III - o tratamento diferenciado para o desporto profissional e o não-profissional;

IV - a proteção e o incentivo às manifestações desportivas de criação nacional. (BRASIL, 1988, on-line). 
Mesmo no intento de trazer uma nova perspectiva política e social para a área esportiva, a Lei Zico passou por diversas modificações, induzidas por pressões advindas de dirigentes de clubes esportivos, em especial no ponto em que a nova lei buscava enquadrar os clubes em sociedades empresariais, regidos, assim, pela legislação civil (BUENO, 2008).

Ademais, as pressões demandadas pelos grupos de interesse engendraram uma legislação cheia de lacunas e ambiguidades. Ainda na etapa de elaboração, Bueno (2008) relata que três grupos agiram na conformação da Lei nº 8.672/1993. O primeiro grupo refere-se à gestão pública, representado pela Secretaria dos Desportos da Presidência da República (SEDES) e pelo Conselho Nacional de Desporto (CND). O segundo grupo era vulgarmente chamado de "bancada da bola" e atuava de forma ostensiva e conservadora. Finalmente, o terceiro grupo de interesse era representado pela comunidade de Educação Física e pelo Colégio Brasileiro de Esporte (CBCE), bem como pela Federação Brasileira de Associações de Profissionais de Educação Física (FBAPEF) (BUENO, 2008).

Por fim, sobre a Lei Zico, “[...] pode se dizer que no jogo da política pública para o esporte, o futebol e o EAR dividem o campo de jogo, a grande massa de potenciais praticantes apenas assiste, mas sem motivos para palmas" (BUENO, 2008, p. 199).

Em 1995, uma nova legislação foi criada no intento de substituir a Lei n 8.672/1993 (Lei Zico). Contudo, pode-se observar que poucas mudanças de fato ocorreram em relação à legislação esportiva de 1993, uma vez que quase a metade dos dispositivos da nova lei é simples transcrições da que a antecede (BOUDIENS, 2002).

Compete destacar que, em 2003, foi instituída a Lei $n^{0} 10.672$, que define que as entidades esportivas, independente da categoria jurídica adotada, estão sujeitas às sanções e responsabilidades impostas pelo Código Civil Brasileiro.

Em 20 de junho de 2004, na I Conferência Nacional do Esporte, foi amplamente discutido o fomento de políticas de esporte e lazer focadas na inclusão social. No governo de Luiz Inácio Lula da Silva, muitas discussões e debates foram realizados, visando agregar a perspectiva universalista ao esporte e ao lazer. No entanto, a Política Nacional de Esporte naquela ocasião ainda estava longe de assegurar o preconizado pela Carta Magna Brasileira, a Constituição Federal de 1988, conforme amplamente debatido na Conferência Nacional de Esporte, em 2004.

Para os membros da I Conferência Nacional do Esporte (2004, p. 14):

\begin{abstract}
É dever do Estado assegurar o direito constitucional de acesso às atividades esportivas e de lazer a toda a população, independentemente da condição socioeconômica ou necessidade especial e qualquer natureza, e do estágio de ciclo de vida de seus distintos segmentos. Mas isso só se realiza de maneira plena em ambiente democrático, como este em que vivemos no Brasil, construído pela sociedade brasileira, e ao contrário de intervenções autoritárias, desconectadas dos anseios populares.
\end{abstract}

A partir das discussões e debates advindos da I Conferência do Esporte, definiu-se a necessidade de criação do Sistema Nacional de Esporte e Lazer. Na II Conferência Nacional do Esporte deu-se continuidade aos debates acerca da concretização do Sistema Nacional de Esporte e Lazer (BUENO, 2008).

Compete destacar que essas discussões se tornaram, no Brasil, mais intensas no presente século, mas foram iniciadas, em um contexto global, ainda no século XX, pelo movimento "Esporte para Todos" (BUENO, 2008).

Bueno (2008) relata que o “Manifesto Mundial do Esporte”, em 1964, incentivava uma reavaliação ideológica do esporte:

O Manifesto denunciou a crise no esporte devido ao excessivo predomínio do EAR [Esporte de Alto Rendimento] e defendeu a implantação de modelo de prática esportiva que também atendesse pessoas comuns (esporte de participação ou de lazer) e ao sistema escolar. (BUENO, 2008, p. 138).

Nesse processo de construção de novas formas esportivas, tanto no ambiente escolar quanto fora dele, foi criado o Sistema Nacional de Esporte e Lazer, que se tornaria um mecanismo capaz de abarcar os 
três eixos esportivos, vinculado a políticas nacionais de gestão participativa e controle social, de recursos humanos e de financiamento e incentivo ao esporte (MINISTÉRIO..., 2004).

No tocante ao incentivo do campo esportivo, em 2006, foi criada a Lei $n^{0} 11.438$, Lei de Incentivo Fiscal ao Esporte, que estabeleceu os benefícios fiscais às pessoas físicas e jurídicas que estimulem o desenvolvimento do esporte nacional por meio de patrocínio para projetos desportivos e paradesportivos.

A Lei de Incentivo ao Esporte permite a utilização de recursos oriundos da referida lei a manifestações desportivas diversas, com exceção do desporto de rendimento praticado de modo profissional.

Vale pontuar que o Estatuto do Desporto determina que os recursos públicos sejam destinados prioritariamente à promoção do esporte educacional e de base, e, em casos específicos, ao esporte de desempenho.

Observa-se que no contexto brasileiro, desde o Estado Novo até o presente momento histórico, foram obtidos importantes avanços no tocante às políticas esportivas, desde a ampliação das dimensões esportivas até o entendimento do esporte enquanto direito social.

Logo, apesar da ampliação de leis que advoguem sob uma nova óptica, existem lacunas e/ou falhas nessas leis que possibilitam essa realidade política e governamental para o universo esportivo.

\section{POLÍTICA PÚBLICA DE ESPORTE NO ESTADO DE GOIÁS: O CASO DO PROGRAMA DE INCENTIVO AO ESPORTE [PRO-ESPORTE]}

Elias (1993) e Elias e Dunning (1985) discorrem que o esporte, conforme o padrão esportivo contemporâneo, desenvolveu-se em meio a um processo civilizatório da Europa Ocidental, em meados do século XVIII, ocasião em que a sociedade moderna passava por mudanças econômicas, políticas e sociais significativas.

O florescimento das práticas esportivas, conforme menciona Dias (2013), advém da articulação entre o ideário de progresso urbanístico e de modernização de valores, costumes e crenças. Quanto ao estado de Goiás, a debilidade no crescimento da região Centro-Oeste até 1930 influenciou na carência de práticas esportivas ou de lazer. Os primeiros movimentos esportivos aparecem, no estado de Goiás, no início do século XX.

Enquanto em São Paulo o futebol já se apresentava como uma modalidade popular e disseminada entre as massas populares, em Goiás essa modalidade, a primeira aqui instalada, foi trazida por Walter Sócrates do Nascimento, considerado o "pai” do futebol no estado (DIAS, 2013, p. 4):

\begin{abstract}
[...] Walter teria começado a organizar matches no Largo do Chafariz, ao lado do Lyceu de Goiás, entre os anos de 1907 e 1908. Em 1911, a cidade já conhecia três equipes, sendo Associação Atlética União Goiana a pioneira. Depois disso, ainda segundo a versão de Alves Filho, o futebol teria se irradiado para outras tantas partes do [E]stado, desde as cidades de Rio Verde e Anápolis, até Jaraguá e Pirenópolis, passando por Inhumas e Itaberaí.
\end{abstract}

O baixo desenvolvimento goiano acabou afetando o baixo desenvolvimento esportivo no estado de Goiás. As práticas esportivas estavam atreladas ao contexto escolar, outrora elas e as práticas de lazer eram bastante escassas e incipientes. De acordo com Dias (2013), aqueles que visitam a região logo percebiam as características rurais, tradicionais e conservadoras que prevaleciam em Goiás:

\begin{abstract}
O viajante inglês Arnold Henry Savage Londor, que esteve na cidade [de Goiás] em 1911, registrou suas impressões sobre a vida do local. Segundo ele, tratava-se de lugar bonito, mas morto, "uma cidade medieval", nas palavras dele, sem pessoas, sem indústria, sem negócios, nem comércio, onde os dias arrastavam-se tediosamente. Seus habitantes pareciam-lhes "apáticos" e "ultraconservadores em suas ideias". O futebol, nesse contexto, mesmo que praticado regularmente, 0 que é incerto, não seria, de todo modo, muito mais que um passatempo de crianças, um mero "bate-bola" [...]. (DIAS, 2013, p. 35).
\end{abstract}

Após a transferência da capital de Goiás para a recém-construída Goiânia, baseando-se na política nacional de desenvolvimento do oeste do país, instituída 
pelo Estado Novo, em 1933, novas configurações surgem em relação ao campo esportivo. Na nova capital, o futebol ascende como esporte prioritário.

Em 1938, foi fundado o primeiro clube esportivo de futebol, o Goiânia Esporte Clube. Outros dois clubes tradicionais da cidade de Goiânia e do estado de Goiás foram fundados em 1943. No ano seguinte deu-se a criação da Federação Goiana de Futebol.

Assim como ocorria no Brasil, o futebol transforma-se no esporte tradicional e hegemônico para a sociedade goiana. Os "coronéis" do futebol, como intitula Tubino (1996), começam a formar coalizões também no subsistema esportivo goiano.

Entre 1960 e 1970, o futebol goiano repercute nacionalmente, vinculado a uma política de incentivo ao esporte de rendimento e de espetacularização do esporte, incentivada pelo governo militar.

O processo de esportivização no regime militar, entre 1964 e 1985, era empregado, visando disciplinar a sociedade, manter a ordem social e obscurecer as ações violentas e ditatoriais praticadas naquela época. O futebol torna-se um elemento fundamental para a disseminação de ideários de patriotismo e de civismo.

Em Goiás eram realizados torneios e campeonatos locais que reproduziam a concepção esportiva nacional, a exemplo dos Jogos Escolares e da Copa BEG. Ou seja, no intento de encontrar talentos esportivos, a escola passa a incentivar a prática esportiva sob o viés do alto rendimento e a estimular eventos esportivos capazes de ludibriar a sociedade, ocultando a realidade social, econômica e política vivida em todo o país.

Logo, percebia-se a necessidade de profissionalização de professores de educação física, com viés tecnicista e com condições de preparar e lapidar, na escola, esses futuros talentos esportivos, bem como garantir a disciplina e a ordem em sociedade. A Escola Superior de Educação Física de Goiás passa a garantir a formação de profissionais com condições de cumprir as necessidades não somente do estado, mas de grupos específicos que possuíam interesses no campo esportivo e econômico. Nascimento (2009) disserta que a fundação de uma Escola Superior em Educação Física “[...] surge com dois objetivos principais: a necessidade de formar professores para o Estado e de fazer disso um fator político bastante vantajoso para o Governo Estadual [...]" (NASCIMENTO, 2009, p. 70).

Após a redemocratização brasileira, ao final da década de 1980, o estado de Goiás ampliou suas ações governamentais para o campo esportivo pautado no processo de descentralização da gestão de políticas públicas de esporte e lazer, instituído pela Lei nº 8.672/1993 e pelo Sistema Nacional do Esporte e Lazer.

O processo de descentralização é considerado um ponto fundamental para a elaboração e a implementação de políticas públicas de esporte e de lazer nas diferentes esferas governamentais. Na referida Conferência definiu-se que "o Sistema Nacional do Esporte e do Lazer pressupõe um processo integrado que compreende um corpo unificado de políticas públicas da União, dos Estados e dos Municípios" (CONFERÊNCIA..., 2004, p. 16).

Na Constituição Estadual de Goiás, a Seção III, do desporto e do lazer, oficializa que as manifestações esportivas, as atividades físicas sistematizadas e os jogos recreativos são direitos de todos e dever do Estado. Ademais, esclarece que os recursos públicos, advindos da esfera estadual, destinam-se à promoção prioritária do esporte educacional, ao esporte destinado ao deficiente e, em casos específicos, ao esporte de alto rendimento.

Dentre os deveres do estado de Goiás, a Constituição Estadual aponta a

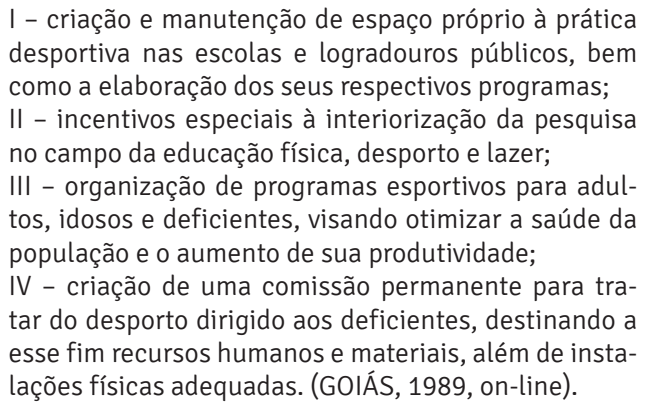

Observa-se um discurso arraigado de ideias e concepções acerca da prática esportiva e de lazer 
como elementos necessários e úteis à formação de corpos robustos, saudáveis e de desempenho satisfatório para a produção laboral. O corpo enquanto máquina, de acordo com Carvalho (2004), é um objeto "idealizado" e mitificado.

O novo (velho) discurso de atividade física como promotora de saúde e "elixir da vida" torna-se institucionalizado não apenas nos textos legais criados pelos legisladores estaduais, mas advém de outros atores que influenciam substancialmente na conformação do modelo esportivo hegemônico.

O PROESPORTE foi criado a partir da Lei $n^{0}$ 14.546, de 30 de setembro de 2003, tendo por objetivo fomentar as diversas práticas esportivas pelo apoio financeiro a projetos desenvolvidos por organizações não governamentais, sejam elas de natureza privada, filantrópica ou pública.

Em 2003, o governo estadual apresentava como titular da pasta o governador reeleito Marconi Perillo, filiado ao Partido da Social-Democracia Brasileira (PSDB), partido de oposição ao governo federal, então presidido por Luiz Inácio Lula da Silva, do Partido dos Trabalhadores (PT), enfatizando-se que a legislação e a política estaduais de esporte seguiam os ditames legais federais, em especial acerca da responsabilidade do Estado em fomentar formas distintas de esporte.

Sobre os recursos destinados ao fomento de práticas esportivas por meio do PROESPORTE, a Lei $n^{\circ}$ 17.906, de 27 de dezembro de 2012, define os seguintes critérios quantitativos, conforme a natureza e a finalidade do desporto,

[...] sendo que $10 \%$ (dez por cento) dos recursos serão destinados ao desporto praticado de forma profissional, $15 \%$ (quinze por cento) para ações desportivas relacionadas às pessoas com deficiência e $75 \%$ (setenta e cinco por cento) ao desporto praticado de forma não profissional. (GOIÁS, 2012, on-line).

O novo arcabouço legal estadual mantém uma interpretação dúbia no tocante ao tipo de esporte a ser incentivado, uma vez que não aparece explicitamente o que vem a ser esporte não profissional. Vale ressaltar que, de acordo com Tubino (2010), existem pelo três di- mensões esportivas, já mencionadas anteriormente na presente pesquisa e que nos documentos legais construídos em âmbito federal evidenciam a necessidade de construção de políticas para o campo esportivo que abarquem essas três dimensões: esporte de rendimento, esporte educacional e esporte de participação.

De acordo com dados apresentados pela página oficial do PROESPORTE, pode-se apresentar o número geral de projetos ou ações financiadas pelo estado nos anos 2012 e 2013. Em 2012, foram aprovados e contemplados com financiamento público 86 (oitenta e seis) projetos/ações de diferentes organizações. Já em 2013 esse número subiu para 236 (duzentos e trinta e seis) instituições contempladas pelo Programa de Incentivo ao Esporte no estado de Goiás.

No ano de 2012, foram destinados aos contemplados pelo PROESPORTE o valor de R\$ 3.483.042,00 (três milhões quatrocentos e oitenta e três mil e quarenta e dois reais), distribuídos conforme demonstra o gráfico a seguir:

Gráfico 1 - Percentual gasto em relação à dimensão esportiva no ano de 2012

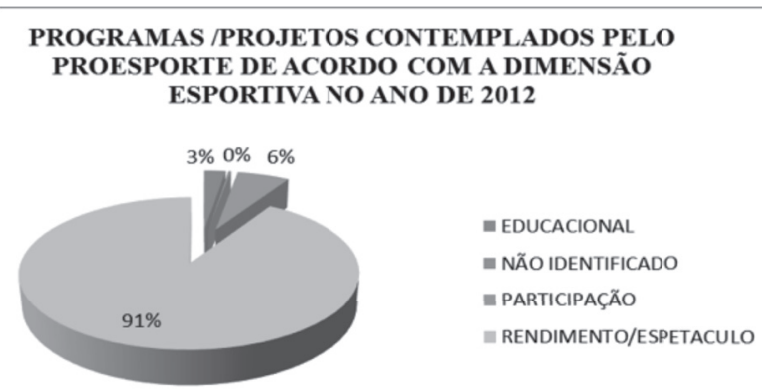

Fonte: Elaborado pela autora, baseado em AGEL/ PROESPORTE (2014).

Observa-se que, em 2012, 91\% (noventa e um por cento) dos beneficiados pela referida política relacionam-se ao tipo esportivo de rendimento. Logo, a apresentação gráfica e o texto normativo-legal estadual permitem afirmar que a gestão governamental, ao examinar e definir os projetos e as ações esportivas a serem contemplados pelo PROESPORTE, tomam suas 
decisões pautados nas decisões advindas da coalizão pró-EAR e dos chamados "cartolas" do futebol.

Isso pelo fato de a Lei n 14.546/2003 apresentar lacunas no tocante a identificar e conceituar as diferentes formas de manifestações esportivas existentes. Logo, a dimensão esportiva mais fomentada e incentivada pela política estadual esportiva vincula-se ao esporte de rendimento, também denominado de esporte de espetáculo.

Essa realidade não se altera no ano subsequente, como aponta o gráfico a seguir:

Gráfico 2 - Percentual gasto em relação à dimensão esportiva no ano de 2013

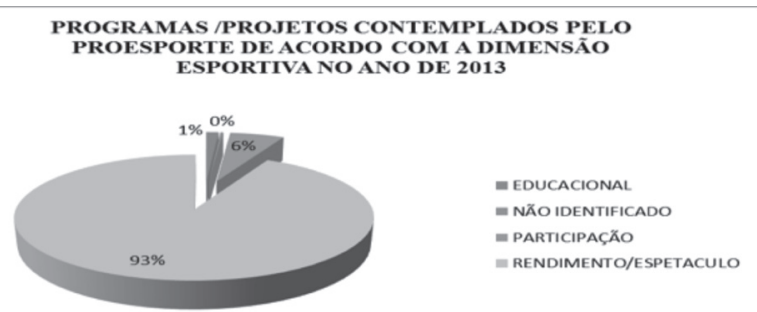

Fonte: Elaborado pela autora, baseado em AGEL/ PROESPORTE (2014).

Pelo contrário, o esporte de rendimento ou esporte de espetáculo teve seu valor percentual aumentado. Em valores monetários, foram destinados a esse modelo esportivo R\$11.504.374,87 (onze milhões quinhentos e quatro mil trezentos e setenta e quatro reais e oitenta e sete centavos), ou seja, $93 \%$ dos programas e projetos beneficiados pelo financiamento público.

O esporte de rendimento pode ser de dois tipos: 0 esporte de rendimento olímpico e o esporte de rendimento paralímpico. A Lei $n^{0} 17.906 / 2012$ especifica que, dos $25 \%$ (vinte e cinco por cento) destinados ao desporto de rendimento, $10 \%$ (dez por cento) devem ser ao desporto profissional e 15\% (quinze por cento) ao desporto praticado pelas pessoas com deficiência (ou seja paradesporto/paralímpico).

Em 2012, foram destinados ao desporto paralímpico o valor de $\mathrm{R} \$ 398.042,00$ (trezentos e noventa e oito mil e quarenta e dois reais), enquanto para o despor- to olímpico foram disponibilizados R\$2.380.000,00 (dois milhões trezentos e oitenta reais).

Gráfico 3 - Percentual gasto em relação ao tipo de esporte de rendimento no ano de 2012

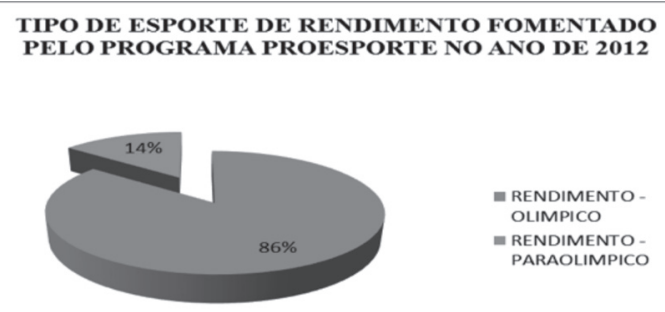

Fonte: Elaborado pela autora, baseado em AGEL/ PROESPORTE (2014).

Em 2013, o valor destinado ao desporto paralímpico teve, em comparação ao ano anterior, um singelo aumento, pois os projetos contemplados pelo PROESPORTE receberam R\$ 435.000,00 (quatrocentos e trinta e cinco mil reais). Contudo, em relação ao desporto olímpico, houve uma redução drástica na concessão de financiamento ao paralímpico. De 14\% (quatorze por cento) do total de programas e projetos contemplados pela Política de Incentivo ao Esporte para o desporto paralímpico no ano de 2012, em 2013 apenas 4\% do universo total de projetos e programas foi destinado ao esporte de rendimento paralímpico.

Gráfico 4 - Percentual gasto em relação ao tipo de esporte de rendimento no ano de 2013

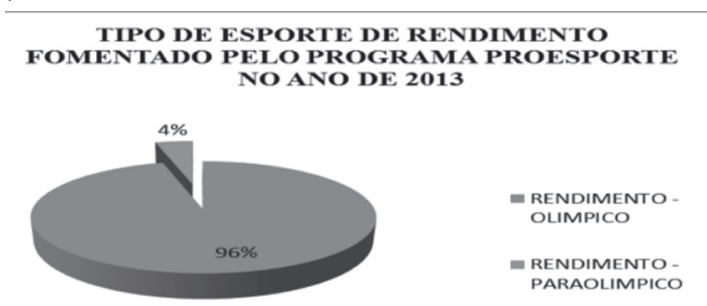

Fonte: Elaborado pela autora, baseado em AGEL/ PROESPORTE (2014). 
Nos dois anos analisados pela presente pesquisa evidencia-se que o esporte de rendimento olímpico é hegemônico no contexto político goiano.

Nesse contexto empreende-se a política estadual de incentivo ao esporte. Para tanto, os projetos devem promover a iniciação esportiva; o estímulo à prática habitual de esportes; o desenvolvimento científico e a pesquisa sobre o campo esportivo; a preservação e conservação de espaços públicos destinados à prática esportiva; fomento do esporte adaptado e o desporto escolar.

A coalizão pró-EAR no estado de Goiás também acaba influenciando ativamente na configuração política e na ação política e governamental. Os meios midiáticos divulgaram, em 2013, a mudança na mencionada lei, visando favorecer o Goiás Esporte Clube pelo financiamento para a construção de estrutura na sede social do clube.

A pesquisa conseguiu compilar, dos dados coletados junto ao site institucional do PROESPORTE, os valores destinados às diversas instituições esportivas, dentre elas o Goiás Esporte Clube, que recebeu, em 2013, R\$ 1.350.000,00 (um milhão trezentos e cinquenta mil reais). Outras associações esportivas tradicionais do futebol goianiense receberam em torno de R\$ 400.000,00 (quatrocentos mil reais), conforme apresentado no quadro a seguir.

Quadro 3 - VALORES DESTINADOS PELO PROESPORTE EM 2013

\begin{tabular}{|c|c|}
\hline PROPONENTE & VALOR DESTINADO (R\$) \\
\hline GOIÂNIA ESPORTE CLUBE & $380.000,00$ \\
\hline GOIÁS ESPORTE CLUBE & $1.350 .000,00$ \\
\hline VILA NOVA & $400.000,00$ \\
\hline
\end{tabular}

Fonte: Elaborado pela autora, baseado em AGEL/ PROESPORTE (2014).

Ademais, as agremiações atléticas e federações esportivas foram as instituições que mais "lucraram" com a referida política de incentivo. Logo, permite-nos afirmar que grupos de interesse no fomento e incentivo do esporte de rendimento foram os atores que influen- ciaram substancialmente na conformação legal, bem como no processo decisório e de escolhas dos grupos beneficiados e contemplados com tal política.

Nesse processo de reflexão sobre as políticas públicas de esporte engendradas pelo governo estadual de Goiás, em especial após a criação de lei específica para o fomento e incentivo do esporte nesse estado, aponta-se, inicialmente, que a elaboração de leis ou normas jurídicas - quando construídas em meio a um espaço de disputas e conflitos de poder, em que existem grupos ou elites que buscam um monopólio político - acaba por apresentar lacunas que propiciam (ex)implicitamente que essas elites esportivas sejam privilegiadas e tenham seus interesses mantidos e cautelados.

\section{CONCLUSÕES}

A política, assim com o esporte, são construções engendradas no seio da sociedade moderna. Ou seja, a partir de um processo de racionalização, especialização e urbanização da sociedade via-se a necessidade de desenvolver condições de essa sociedade se relacionar e interagir sem precisar empreender ações violentas ou destrutivas.

O parlamento se torna um espaço para discussões e decisões políticas, enquanto praças, jardins e ginásios destinam-se à prática de atividades esportivas, visando a melhoria da saúde e o potencial produtivo do homem. Claro que não foram abolidas as ações militares, logo, o esporte tratava de preparar os soldados para possíveis batalhas.

A racionalização do esporte permitiu a difusão de modalidades distintas, a princípio no berço do esporte moderno, a Inglaterra. Contudo, as relações comerciais e políticas entre Europa e o continente americano permitiram a disseminação dessas práticas esportivas.

0 crescimento do campo esportivo no Brasil foi visto por grupos específicos como um fenômeno econômico e político oportuno aos seus interesses, grupos esses que seriam chamados futuramente, por estudiosos da área, de "coronéis" ou "senhores feudais" do esporte. 
A predominância do esporte de alto rendimento, também denominado de esporte-espetáculo, em determinados momentos políticos foi utilizada como mecanismo para controlar e disciplinar a sociedade brasileira. E mais, como Bourdieu (1996, 2003, 2004, 2011) aponta, o campo esportivo propiciou a legitimação de estilos de vida, de tipos de corpos e, claro, de tipos de esporte.

A análise construída a partir de documentos e levantamentos oficiais permitiu-nos confirmar as hipóteses tratadas no presente estudo quanto ao modelo esportivo predominante na realidade goiana, bem como que coalizões ou grupos específicos, citam-se os clubes de futebol, têm se beneficiado da política de incentivo ao esporte no estado de Goiás.

No contexto goiano reverbera o mesmo tipo de interação e relação que se vê em âmbito federal no tocante aos grupos empresariais esportivos e ao estado. As leis são elaboradas, políticas são construídas e implementadas e a gestão pública as executa disseminando crenças e valores que corroborem a ascensão e manutenção do status quo desses grupos detentores de poder não apenas econômico, mas político.

Assim, podemos refletir, finalmente, que as decisões deliberadas desde o processo de inserção do tema esportivo na agenda governamental até as ações empreendidas pelos burocratas da esfera executiva estadual apresentam uma permeabilidade de interesses que foram apresentados pela pesquisa documental e análise de dados extraídos de documentos oficiais governamentais, relatórios e páginas institucionais. Ou seja, essa relação entre mercado e Estado deixa evidenciada que no contexto político e da gestão pública goiana, quanto ao campo esportivo, as políticas públicas formuladas e implementadas favorecem segmentos e privilegiam o esporte de rendimento, mantendo vivos os "senhores feudais", também chamados "coronéis", do esporte.

\section{REFERÊNCIAS}

AGÊNCIA Goiana de Esporte e Lazer. Apresentação do Programa Estadual de Incentivo ao Esporte PROESPORTE. Goiás, 2014.
BOUDENS, E. Legislação Desportiva Brasileira: uma visão panorâmica. Consultoria Legislativa, Câmara dos Deputados, Brasília/DF, 2002.

BRASIL. Constituição Federal. Vade Mecum. 5. ed. São Paulo: Saraiva, 2008.

BRASIL. Lei no 8.672, de 06 de julho de 1993. Institui normas gerais sobre desporto, e dá outras providências. Diário Oficial da União, Brasília-DF, 1993. Disponível em: http://www2.camara.leg.br/ legin/fed/lei/1993/lei-8672-6-julho-1993-349784publicacao original-1-pl.html. Acesso em: 11 jul. 2013.

BRASIL. Lei no 9.615, de 24 de março de 1998. Institui normas gerais sobre desporto, e dá outras providências. Diário Oficial da União, Brasília/DF, 1998.

Disponivel em: http://www.planalto.gov.br/ccivil_03/ leis/19615consol.htm. Acesso em: 1 jul. 2013.

BRASIL. Lei no 9.981, de 14 de julho de 2000. Altera dispositivos da Lei no 9.615 , de 24 de março de 1998, e dá outras providências. Diário Oficial da

União, Brasília/DF, 2000. Disponível em: http://www. planalto.gov.br/ccivil_03/leis/L9981.htm.

Acesso em: 16 maio 2014.

BUENO, L. Políticas Públicas do Esporte no Brasil: razões para o predomínio do alto rendimento. Tese (Doutorado) - Escola de Administração de Empresas de São Paulo, São Paulo: FGV, 2008.

\section{CONFERÊNCIA Nacional do Esporte. Documento}

Final: Política Nacional do Esporte. Brasília-DF: 2004.

ELIAS, N. 0 processo civilizador: formação do Estado e civilização. v. 2. Rio de Janeiro: Jorge Zahar, 1993.

ELIAS, N; DUNNING, E. A busca da excitação.

Lisboa: DIFEL, 1985.

\section{GOIÁS. Constituição Estadual do Estado de}

Goiás. Gabinete Civil, 1989. Disponível em: http:// 
www.gabinetecivil.goias.gov.br/constituicoes/ constituicao_1988.htm. Acesso em: 22 nov. de 2014.

GOIÁS. Lei nº 14.546, de 30 de setembro de 2003. Dispõe sobre a criação do Programa Estadual de Incentivo ao Esporte - PROESPORTE e dá outras providências. Diário Oficial do Estado de Goiás, Goiás, 2003.

GOIÁS. Decreto n 5.933, de 20 de abril de 2004. Regulamenta a Lei $n^{0} 14.546$, de 30 de setembro de 2003, que dispõe sobre a criação do Programa Estadual de Incentivo ao Esporte - PROESPORTE e dá outras providências. Diário Oficial do Estado de Goiás, Goiás, 2004.

GOIÁS. Decreto n 7.454, de 8 de setembro de 2011. Aprova o Regulamento da Agência Goiana de Esporte e Lazer e dá outras providências. Goiás, 2011. Disponível em: http://www.segplan.go.gov.br/post/ ver/108955/agel. Acesso em: 22 nov. 2014.

GOIÁS. Lei n⿳0 17.906, de 27 de dezembro de 2012. Altera a Lei no 14. 546, de 30 de setembro de 2003, que dispõe sobre a criação do Programa Estadual de Incentivo ao Esporte - PROESPORTE. Goiás, 2012. Disponível em: http://www.segplan.go.gov.br/post/ ver/108955/agel. Acesso em: 22 nov. 2014.

\section{KUNZ, E. Transformação didático-pedagógica do esporte. Ijuí/RS: UNIJUÍ, 2000.}

MENICUCCI, T. Políticas de esporte e lazer: O estado da arte e um objeto em construção. In: ISAYAMA, Hélder Ferreira; LINHALES, Meily Assbú. Sobre lazer e política: maneiras de ver, maneiras de fazer. Belo Horizonte: Editora UFMG, 2006; Barueri, SP: Manole, 2003. p. 179-202.

MINISTÉRIO do Esporte. Conferência Nacional do Esporte. Documento Final. Brasília-DF, 2004.

NASCIMENTO, F. A. R. ESEFFEGO: Imagens do pioneirismo da Educação Física em Goiânia. 2009.
Dissertação (Mestrado) - Programa de Pósgraduação em Cultura Visual, Goiânia, 2009.

PARREIRA, F. R. Corpo Marginal: O Processo de Inclusão Social nas Políticas Públicas desenvolvidas pela Secretaria Municipal de Esporte e Lazer, no Município de Goiânia, entre 1997 a 2013. 2014. Dissertação (Mestrado em Ciência Política) Universidade Federal de Goiás, Goiânia, Goiás, 2014.

SABATIER, P. A. Political science and public policy. In: THEODOULOU, S. Z.; CAHN, M. A. Public Policy: the essencial readings. Upper Saddle River/NJ: Prentice Hall, 1995.

SABATIER, P. A; WEIBLE, C. M. The Advocacy Coalition Framework: Innovations and Clarifications. In: SABATIER, P. A. Theories of the Policy Process. Boulder/Colorado: Westview Press, 2007.

SIGOLI, M. A; ROSE Jr, D. A História do uso político do esporte. Revista Brasileira de Ciência e Movimento, v. 12, n. 2, p. 111-119, 2004.

SOUZA, C. Políticas Públicas: uma revisão de literatura. Revista Sociologias, Porto Alegre, ano 8, n. 16, jul./dez. 2006i.

SOUZA, C.; NETO, P. F. D. Governo, políticas públicas e elites políticas nos estados brasileiros. Rio de Janeiro, RJ: Revan, 2006.

\section{STAREPRAVO, F. A. Políticas públicas de esporte} e lazer no Brasil: Aproximações, intersecções, rupturas e distanciamentos entre os subcampos político/burocrático e científico/acadêmico. 2011. Tese (Doutorado) - Programa de Pós-graduação em Educação Física, Paraná: UFPR, 2011.

TREVISAN, A. P.; VAN BELLEN, H. M. Avaliação de Políticas Públicas: uma revisão teórica de um campo em construção. RAP, Rio de Janeiro, v. 42, n. 3, p. 529-550, maio-jun. 2008. 
TUBINO, M. J. G. Estudos brasileiros sobre o

esporte: ênfase no esporte-educação. Maringa:

Eduem, 2010.

Recebido em: 11 de Outubro de 2017

Avaliado em: 29 de Julho de 2018

Aceito em : 14 de Dezembro de 2018
1 Doutoranda em Sociologia - UFG; Mestra em Ciência Política - UFG; Cientista Social - UFG; Graduada em Educação Física - UEG; Servidora Pública na Secretaria de Estado da Saúde do Estado de Goiás;

Subcoordenadora de Atenção Integral à Saúde do Homem - SES/Goiás. Email: fernandarparreira@gmail.com

2 Especialista em Treinamento Funcional e Condicionamento Físico UNILEYA; Graduado em Educação Física - UNIVERSO; Servidor Público na Superintendência de Vigilância em Saúde, na Secretaria de Estado da Saúde do Estado de Goiás. Email: valimjp@gmail.com 